DOI 10.15393/j9.art.2017.4421

УДК 821.161.1.09“18”

Татьяна Игоревна Хоруженко

Уральский федеральньй университет имени первого Президента России Б. Н. Ельиина (Екатеринбург, Российская Федерация)

tkhoruzhenko@mail.ru

\title{
МОТИВ ВТОРОГО ПРИШЕСТВИЯ В СОВРЕМЕННОЙ РУССКОЙ ФЭНТЕЗИ
}

Аннотация. Мотив Второго пришествия занимает особое место в российской фантастике рубежа двух тысячелетий. В последние десятилетия библейские аллюзии все чаще проникают в жанр фэнтези. Целью статьи было проанализировать особенности воплощения мотива о Втором пришествии в русской фэнтези. Материалом послужили произведения современных авторов Ю. Вознесенской, Н. Перумова, В. Хлумова, С. Лукьяненко и Т. Устименко. В каждом из рассмотренных текстов возникает история Второго пришествия. При этом отношение к образу Спасителя и его повторному пришествию в мир варьируется: от почтительного ожидания (Ю. Вознесенская, Т. Устименко, С. Лукьяненко) до изображения Спасителя как монстра (Н. Перумов). Возможность амбивалентной трактовки Спасителя - ярчайшее свидетельство десакрализации образа. Можно говорить о том, что в современной фэнтези появилась тенденция профанировать сакральные образы, мотивы и сюжеты, что, безусловно, показывает актуальность евангельских сюжетов для массового сознания.

Ключевые слова: Второе пришествие, русская фэнтези, фантастика, массовая литература, Евангелие, библейские аллюзии

$\mathrm{M}$ отив Второго пришествия Христа достаточно распространен в русской литературе. В экспериментальном словаре-указателе сюжетов и мотивов под редакцией Е. К. Ромодановской он выделен в отдельную статью «Второе пришествие Христа / Лжехристос. Ср. Антихрист (а). Попытка повторить пришествие Христа/ новый Мессия» $[13,34]$. И. А. Есаулов утверждает, что «русская словесность первых семи веков своего существования отчетливо христоцентрична, то есть изначально ориентирована прежде всего на Новый Завет» [3, 440]. Можно говорить о том, что евангельские сюжеты и мотивы сохраняются и в новейшей литературе. 
Осмысляя причины привлекательности мотива Второго пришествия для русских авторов XIX-XX вв., Н. А. Бирюзова отмечает: «В мифе о Втором Пришествии писателей привлекает исключительная личность Христа, в которой воплотились духовное совершенство и морально-этические ценности, необходимые человечеству» $[1,17]$. Потребность в безусловных нравственных ориентирах ведет к тому, что писатели в той или иной форме обращаются к новозаветным сюжетам.

«Очевидно, что евангельские тексты и их многочисленные интерпретации входят в число важнейших смыслопорождающих структур уже не только европейской, но и всей мировой культуры, - пишет И. Кукулин. - Даже для людей внецерковных, неверующих или принадлежащих к нехристианским конфессиям эти тексты имеют значение философских метафор, позволяющих говорить о месте человека в мире и обществе, о ситуациях нравственного выбора, совершаемого с риском для жизни, о свободе и предательстве. Поэтому любое изложение евангельских событий, сделанное с сознательными отклонениями от канона, претендует на ревизию глубинных культурных и экзистенциальных смыслов» [7, 402].

Критик Я. Кротов предлагает даже выделить особый жанр «евангельская фантастика», охватывающий всю совокупность романов о Христе: «Романы о Христе отличны не только от апокрифов и переложений Евангелия в ту или иную форму. Они составляют особый жанр современной литературы. Жанр этот вторичен и стилистически часто подражателен <...>. Есть детективный жанр, есть фэнтези, есть фантастика научная, а есть евангельская фантастика. Надо бы ее назвать (она, между прочим, до сих пор не опознана как жанр) "христианская фантастика", да только “христианское”, к сожалению, означает не “относящееся ко Христу”, а “относящееся к христианам"» $[5,243]$.

При интерпретации религиозных мотивов и сюжетов в литературе в целом и в фантастике в частности отмечается ряд проблем. А. В. Татаринов подчеркивает, что в литературе христианские сюжеты, мотивы и образы оказываются в пространстве вымысла, что неизбежно ведет к их трансформации: «Художественные тексты о евангельских событиях, используя 
архетипические для христианской культуры имена (Бог, Иисус или Мария), фабульные знаки (крещение, искушение в пустыне или распятие), речи (Нагорная проповедь или полемика с фарисеями), остаются в пространстве вымысла...» [14]. Таким образом, любое художественное произведение, взявшее за основу сюжета Евангелие, неизбежно трансформирует канон. Я. Кротов подчеркивает: «Христос у верующего вверху, у евангельских фантастов - под пером. Вера играет в данном случае совершенно ту же роль, что наука в случае с научной фантастикой. В научной фантастике мало науки, в евангельской фантастике мало веры. Это не итог анализа, это условие анализа, аксиоматический признак» $[5,243]$.

Современная фантастика продолжает общую тенденцию русской литературы и достаточно регулярно обращается к евангельским сюжетам. Е. Чепур подчеркивает, что «противоречивость и феноменальность фэнтези заключается в том, что, признанная богоборческой, она открывает авторам возможность богоискательства» $[16,190]$. В связи с этим в русской фэнтези предлагается выделять особый тип героя - богоискатель. В то же время, как отмечает Е. М. Неёлов, религиозные сюжеты оказываются в фантастическом произведении как бы во «враждебной среде» $[10,385]$. По мнению исследователя, «христианская традиция (не в культурном, но собственно религиозном качестве) требует веры, а фантастика, как фольклорная, так и литературная, всегда строится на сознательной установке на вымысел. Вера принципиально противопоказана фантастическому произведению, даже научно-фантастическому» $[10,384]$.

В то же время Е. М. Неёлов, говоря о христианской традиции в русской фантастической литературе рубежа веков, выделял два способа ее проявления: «Во-первых, она представлена на уровне жанрового содержания произведения, во-вторых, на уровне его содержания непосредственного» [10, 379]. Мы остановимся на нескольких фантастических произведениях конца XX - начала XXI вв., в которых Второе пришествие Спасителя - основа сюжета.

В русской фэнтези можно выделить несколько произведений, разрабатывающих идею Второго пришествия, а именно: 
дилогия «Искатели неба» С. Лукьяненко (1997, 1999-2000), «Старая дева Мария» В. Хлумова (1997), «Летописи разлома» Н. Перумова (2006), «Приключения Ланселота» Ю. Вознесенской (2003). Кроме того, в последнее десятилетие сформировался пласт фэнтези-текстов, в которых человек становится богом и как бы возвращается в мир, некогда оставленный Богом (или богами). Один из них - роман Т. Устименко «Богами не рождаются» (2009), который будет рассмотрен в данной статье.

Примечательно, что почти все анализируемые тексты были созданы на рубеже тысячелетий. Как отмечают Е. И. Петухова и И. В. Черный, «писатели, с одной стороны, не могут пройти мимо такого явления, как смена эпох. Они как бы подводят некую черту под своим творчеством, желая разграничить все, написанное в XX веке, и то, что будет создано в веке XXI. С другой стороны, как это почти всегда бывает в ситуациях, подобных этой, в литературе усиливаются эсхатологические тенденции» [12].

Сразу оговоримся, что два из пяти рассматриваемых текстов могут быть отнесены к фэнтези с некоторой натяжкой. Речь идет о повести В. Хлумова «Старая дева Мария» и о романе Ю. Вознесенской «Приключения Ланселота». Повесть Хлумова могла бы быть притчей, однако она почти полностью лишена назидательности. Роман Ю. Вознесенской, в свою очередь, находится на границе фэнтези и антиутопии.

Во избежание терминологической путаницы необходимо оговорить наше понимание фэнтези. В своей статье мы следуем за Е. Н. Ковтун, определяющей фэнтези как «литературу, в пространстве которой возникает эффект чудесного; в ней присутствуют в качестве основного и неустранимого элемента сверхъестественные или невозможные миры, персонажи и объекты, с которыми герои и читатель оказываются в более или менее тесных отношениях» $[4,78]$. Важно подчеркнуть именно чудесность, лежащую в основе фэнтези. Этот жанр, в отличие от научной фантастики, не допускает рациональной трактовки мира и происходящих с героями событий.

Как легко заметить, воспроизведение / переосмысление евангельских сюжетов, по определению чудесных, 
укладывается в данное определение. Герои всех анализируемых произведений встречаются с невозможным (Спасителем, ангелами, искусителями и т. д.) или же сами становятся таковыми.

Мотив Второго пришествия в фантастических текстах часто подвергается трансформациям. В частности, неоднозначно изображается спаситель мира: он может оказаться и «погубителем», и подлинным «искупителем». Ориентация на Священное Писание сохраняется только на уровне фабульного ряда, аксиологический смысл заимствуемой истории может игнорироваться. Достаточно вольное отношение авторов-фантастов к евангельским текстам также позволяет им свободно брать за основу разные эпизоды новозаветной истории.

Так, в произведении В. Хлумова «Старая дева Мария» героиня по имени Мария получает три послания о том, что у нее родится сын, призванный стать новым спасителем человечества. Благая весть приходит Марии через письма. При этом подчеркивается белизна конверта и фривольное содержание марки, наклеенной на него:

Почерк - гарнитура «Таймс», подпись неразборчивая, прокомментировала Маша, покрутила конверт, сияющий девственной, не тронутой почтовыми службами, свеженькой, с острыми зубчатыми краями маркой, на которой Мария шлепает по голому розовому задку маленького Иисуса Христа, из собрания Метрополитен Мьюзиум, что в Нью-Йорке ${ }^{1}$.

В письмах к Марии, незамужней женщине, не знавшей мужчины, сообщается о том, что она носит во чреве «того, кто явлен будет миру дважды, ибо тот, кто был первый раз судим, в другой раз судить будет». Примечательно, что счет дней в посланиях идет от даты предполагаемого рождения: «За восемь месяцев и три недели до рождества». Отметим, что автор в данном тексте, по сути, не столько воспроизводит сюжет о Втором пришествии, сколько - о Благовещении.

На пути к своей судьбе Мария встречает искусителя своего коллегу Верзяева, которого она любит и от которого хочет зачать ребенка. «Змей-искуситель», как его называет автор, погибает в автомобильной катастрофе. Сразу после 
этого Мария встречает «ангела-товарища» Виктора, который и становится ее хранителем.

Именно Виктор и объясняет Марии, что «та первая» была обычной женщиной, такой же, как она:

- Почему Бог избрал меня - простую, бестолковую женщину? <..> Да, из тысяч и миллионов ничем не примечательных женщин. Ведь та, первая, была особенной.

- Ой-ли?! - Виктор потянул на себя правый рычаг, и они, проплыв над домом Пашкова и восстановленным Храмом Христа, легли на прямой курс вдоль широкого проспекта, упиравшегося в горы имени Ленина.

Как выясняется, особенность Марии состоит в готовности к любви и состраданию:

Ведь чудо господне не в исцелениях и хождениях по водам, не в полетах в межоблачном пространстве, ни, господи меня помилуй, в глотании ножей и всяческой прочей азиатчине, чудо в том, что вы, атеистка с молодых корней и молочных соков, живете так, как будто есть еще что-то, кроме вампиров, Воландов да ..... Черного Барона, да, мало того, что живете, еще и любите, любите и знаете, что Господь Бог не три буквы на трафаретке или Всемогущее Ничто. Ведь готовы плакать не только над той Девой, но и над «Просто Марией»!

В финале повести Мария, смирившись со своим предназначением, выходит замуж за пожилого и давно влюбленного в нее профессора Иосифа. Отметим, что автор и его герои достаточно скептически относятся ко всему происходящему с ними. Ирония становится главной интонацией всего произведения.

Роман «Приключения Ланселота» Ю. Вознесенской (продолжение романа «Путь Кассандры, или Приключения с макаронами») изображает Второе пришествие достаточно канонично: Антихрист, ложно принимаемый за Мессию, побежден, а подлинный Спаситель приходит в разрушенный Третьей мировой войной мир. Важно подчеркнуть, что приход Спасителя завершает роман и Его образ не описывается - 
герои, прошедшие сложный путь обретения веры, видят Его со спины:

Двери храма распахнулись, и из них вышел высокий Священник в ослепительно белых одеждах. Дженни и Ланселот видели его со спины, видели падающие на плечи кудри русых волос, но не видели лица. За ним шли священнослужители в таких же радостных пасхальных одеяниях, монахи и монахини, мирские мужчины и женщины, старики и дети. Священник в белом, идущий впереди всех, медленно шел по дороге из храма и вел за Собой остальных. Они не видели Его лица, потому что он шел почти спиной к ним, уходя от них еще выше по горе. А люди все выходили и выходили из храма, и было абсолютно непонятно, как в этом небольшом храме помещалось столько людей, и как это так получается, что идущего впереди всех Священника они продолжают видеть, хотя за ним прошли уже, наверное, тысячи людей. ${ }^{2}$

Второе пришествие Христа происходит возле Иерусалима, резиденции Мессии, на Гефсиманском острове.

Тексты Ю. Вознесенской часто относят к «православной фэнтези». Отметим, что Е. М. Неёлов резко возражал против подобного определения: «...нет и не может быть жанра “христианской фэнтези”, о котором говорят некоторые авторы в связи с творчеством, в частности, Ю. Вознесенской. Ее книги, глубоко православные по непосредственному содержанию, исполненные истинной веры, критик <Е. А. Павликова [11]> почему-то называет “фэнтези”, всякую веру как раз разрушающую» $[10,384]$. М. Крылова предлагает относить романы писательницы к жанру «постапокалипсиса (постапокалиптики)» $[6,103]$, а С. Бойко - к жанру антиутопии. В то же время, по мнению последней исследовательницы, тексты Ю. Вознесенской содержат в себе «приметы сказки: путешествия по неведомому миру, встречи со сверхъестественными существами, загадки, образы добрых помощников и многое другое» [2, 87]. По мнению М. Крыловой, «перед нами смешение жанров: постапокалипсис, фантастика, фэнтези, даже сказка...» $[6,109]$. Между тем, на наш взгляд, тексты Ю. Вознесенской все же представляют собой фэнтези.

В основе сюжета романа «Паломничество Ланселота» лежит история обращения в истинную веру неверующего и с Божьей 
помощью победа над Мировым Злом. Герой романа — инвалид Ларс - отправляется к Антихристу, правящему миром, за исцелением. При этом физический путь героя совпадает с его нравственным совершенствованием. В финале герой перерождается как физически, так и духовно.

В конце дилогии Лже-Мессия побежден главным героем, уверовавшим в Христа и отвергшим дьявольское исцеление:

- Ты не Мессия, - сказал Ланселот. - Мессия - другой, и Он уже приходил в этот мир. Ты - Антихрист, убийца людей и погубитель мира. Я отказываюсь от твоего исцеления и плюю на тебя!

<...> Антихрист завизжал и схватился обеими руками за лицо. И все увидели, как его лицо полыхнуло коротким синим пламенем, а руки превратились в покрытые рыжей шерстью лапы с длинными черными когтями ${ }^{3}$.

Ланселот, ранее не веровавший в Христа и распятый Мессом на кресте, становится новым мучеником, что заменяет ему крещение, о чем ему и сообщают его православные друзья.

В романе Ю. Вознесенской отчетливо звучит тема православной веры - только последняя, по мысли автора, может спасти человека. Противостоит православным героям ЛжеМессия - воплощение Антихриста. По Планете (название уцелевших после третьей мировой войны частей Европы и Америки) ходят армии клонов, людям назначен срок принудительной эвтаназии, едят заменители пищи и живут в созданной Реальности, где все «планетяне» могут быть теми, кем захотят. Есть единая церковь, и все подданные дважды в день поют гимн во славу Лже-Мессии. Живет Месс на сотом этаже Вавилонской башни в городе-острове Иерусалиме.

Роман Ю. Вознесенской, в отличие от всех остальных текстов о Втором пришествии, стремится максимально полно и серьезно реализовать этот евангельский мотив. При этом автору скорее удается воплотить «дух», а не «букву».

Теперь обратимся к романам, в которых представлены трансформации формального событийного ряда новозаветного сюжета. Так, в дилогии С. Лукьяненко «Искатели неба» рисуется мир, условно похожий на Европу, жители которого веруют в Спасителя, пасынка Божьего, и его Сестру: 
Две тысячи лет назад Искупитель, которому судьбой иная жизнь предназначалась, за добродетели свои стал Господу приемным сыном, отражением его земным. И пошел по земле арамейской, вокруг себя апостолов собирая. Не силой, не убеждением даже, любовью и добротой. Сами к нему люди приходили, прошлое свое отвергая... и были среди них и военный, и вордушегубец, и даже сборщик податей, что уж совсем последнее дело... Всех принял, всех простил, всех в Истинную Веру направил...

А потом попал Искупитель под земной суд, по лживым наветам священников иудейских. Одиннадцать апостолов от него отреклись, предали, пусть и сами того не понимая, а лучшего желая. Один лишь верность сохранил, да еще Сестра, которая и не Сестрой тогда была, а простой женщиной Марией Башенной... Смешна была римлянам вера, не признали они Искупителя сыном Божьим сразу. И только когда сотворил Искупитель подлинное чудо, Слово произнес - не стены темницы руша, а всего лишь оружие вокруг себя в Холод убирая, Сестру спасая, только тогда коснулся римских солдат свет веры. Упали они на колени перед Искупителем, из темницы его вывели и пошли с ним до самого Рима, вечного города, где уж склонились перед Пасынком Божьим все - от цезаря до последнего раба... ${ }^{4}$

В центре повествования оказываются два героя - подросток Марк, владеющий древним Словом, и вор Ильмар. Первый считает себя Искупителем, второй постоянно задается вопросами истинной веры. Именно Ильмару, не считающему себя новым мессией, снится Искупитель:

Снился мне ад.

Ледяная пустыня - без конца, без края. Небо - темное, ни звезды нет, но льется с него тусклый серый свет. И холодно. <...>

А передо мной - столб. Деревянный столб, покрытый иголочками изморози.

И человек на нем - привязанный, прикрученный, с руками за спиной, вокруг столба обвитыми, кожа льдинками колючими затянута, голова поднята - будто пытался в последний раз в небо взглянуть.

В пустое, серое, выцветшее небо...

В то же время древнее пророчество гласит, что приходу Спасителя будет предшествовать приход Искусителя и различить их будет непросто: 
Как сказано в откровениях грешного апостола Иоанна Богослова, прежде должен прийти в мир ложный мессия, тот, что лишь выдавать себя станет за настоящего. А делать все наоборот. Как Искупитель был сыном простых людей, так антипод его, Искуситель, - дитем знатных родителей. Как Искупитель на римский престол взошел, неся в мир закон и порядок, так его порочный двойник от земного престола отречется. Искупитель в мир принес Слово, давшее великую власть над любыми вещами, а Искуситель захочет над живыми душами властвовать ${ }^{6}$.

Примечательно, что Марк, считающий себя новым Искупителем, - младший принц правящей династии.

Сюжет дилогии строится в соответствии с новозаветной историей: «спаситель» находит себе учеников-последователей из разных социальных слоев. Всего новых апостолов двенадцать. В конце концов, Марк являет чудо, вернув взятое две тысячи лет назад железо:

Маркус будет освобождать взятое на Слово постепенно, в каждом городе или селении, куда войдет. Слава его будет расти, все новые и новые люди присоединятся к его армии, и в Рим он войдет уже царем земным.

Не Искупителем.

Не Искусителем.

Всего лишь правителем мира ${ }^{7}$.

После явленного чуда от новых апостолов уходит Ильмар. Он покидает своих спутников и направляется через пустыню к озеру:

Две маленькие рыбацкие лодки стояли на берегу, а рыболовы, вышедшие из них, вымывали сети.

Я посмотрел в небо - и небо затаило дыхание.

Я пошел к берегу ${ }^{8}$.

Финал романа сопоставим с евангельским текстом: «...увидел Он две лодки, стоящие на озере; а рыболовы, выйдя из них, вымывали сети» (Лк. 5:2). Таким образом, финал дилогии остается открытым: Второе пришествие Искупителя только ожидается. Не случайно, именно Ильмару снится вещий сон, в котором он прощает Искупителя: 
И я протянул руку, разрывая веревку, державшую Искупителя. Веревку, завязанную им самим, слишком поздно понявшим свою ошибку'.

Как подчеркивает Н. Кургузова, эта сцена - «своеобразный пик его духовности, он отпускает Искупителя, отпускает ему его грех, прощает его и принимает путь, которым не смог пройти Искупитель» $[8,239]$.

Интересно отметить, что повествование в дилогии С. Лукьяненко ведется от лица Ильмара, - таким образом читатель получает возможность наблюдать за становлением героя. Как отмечает Е. Чепур, «попытка установления зыбкой границы между богоугодным и греховным раскрывает в нем (в Ильмаpe. - T. Х.) богоискателя. Внутреннее состояние поиска героя определяет способ повествования: оно ведется от первого лица и содержит момент исповедальности» $[15,16]$. Исследовательница подчеркивает, что «воскресение грешника Ильмара соответствует логике развития характера, но главное авторской вере в человека» $[15,16]$.

Наиболее радикально образ Спасителя трансформируется в романах цикла «Летописи Разлома» Ника Перумова. Созданный им персонаж оказывается вампиром, пожирающим миры:

Спаситель оставляет пустую оболочку от еще одного мира. <...>

Что же ты такое, Спаситель? Слова о «воплощении людских чаяний» слишком общи. В конце концов, ты разрушаешь миры, ты поглощаешь людские души - во множестве ${ }^{10}$.

Важно отметить, что таким образом Перумов полемизирует и с новозаветными текстами, поскольку фэнтезийный бог забирает (т. е. пожирает) души поклонявшихся ему в гибнущем мире, а не спасает их.

При этом приход Спасителя содержит в себе евангельские аллюзии - человек в рубище спускается с неба:

Небеса раскрылись. Словно на церковной фреске, из рассеченного небосклона к земле протянулась призрачная лестница, тысячи тысяч отливающих золотом ступеней. И по ним неспешно, словно сознавая собственное могущество, спускалась сияющая человеческая фигурка. Нарушая все законы естества, она видна была во всех деталях, словно находилась на расстоянии вытянутой руки. 
Старый хитон. Стоптанные сандалии <...>. Жесткая черная бородка, скорбно-спокойный взгляд ${ }^{11}$.

Это явление Спасителя в небесах отсылает к евангельскому тексту: «...тогда явится знамение Сына Человеческого на небе; и тогда восплачутся все племена земные и увидят Сына Человеческого, грядущего на облаках небесных с силою и славою великою» (Мф. 24:30).

В романе Н. Перумова приход Спасителя означает неминуемый конец мира. Его пытаются остановить маги, а также другие боги. В итоге схватки противникам удается обнажить истинное лицо бога:

...Спаситель выглядел неважно. Посох его обуглился, хитон превратился в лохмотья, едва прикрывавшие наготу, по груди и рукам расползлись пятна обширных ожогов, борода и усы сгорели, скорбный лик мудрого и всепрощающего божества обернулся свирепой и кровожадной маской. Почти выжгло один глаз, второй смотрел мутно и куда-то в сторону ${ }^{12}$.

Отметим, что победа над Спасителем не избавляет мир от гибели: конец света все же наступает. В финале романа два мира соединяются в один, а люди, населявшие их, теперь существуют бок о бок.

Рассмотренные нами произведения раскрывают разные элементы евангельского мотива Второго пришествия: в повести В. Хлумова Спасителю только предстоит родиться в мире заново, роман Ю. Вознесенской показывает сам момент Второго пришествия мессии, дилогия С. Лукьяненко посвящена осознанию и принятию Искупителем своего пути, для Н. Перумова важным становится конец времен, связанный со Вторым пришествием. Каждый автор по-своему интерпретирует и перерабатывает один сюжет, а отношение к образу Спасителя колеблется от восторженного почитания через иронию к изображению его в качестве монстра.

Роман Т. Устименко "Богами не рождаются» на первый взгляд отличается от всех вышеизложенных вариантов Второго пришествия. Главная героиня романа - пилот космического корабля Ника - покинула Землю на тысячу лет. По возвращении она узнает, что объявлена на родной планете святой. Кроме того, сама планета находится на грани гибели. 
Сюжет строится вокруг инициации Ники в бога и спасения уцелевшего населения Земли. Таким образом, Ника также становится спасителем человечества.

При этом сама героиня сопротивляется инициации, превращающей ее в божество:

Я поняла: итог всего - одиночество. Боги - одиноки. Они сознательно, до капли, до последнего вздоха вымораживают из себя все живое: любовь, нежность, дружбу, милосердие. И это есть цена их совершенства. Они непоколебимо уверены в том, что бог - это нечто глобальное и великое, а на самом деле они превращаются в ничто: ведь совершенство так уязвимо! И только осознав все это, я вновь ощутила себя тем, кто, по сути, и является настоящим венцом бытия, - я ощутила себя человеком, со всеми присущими ему слабостями и достоинствами ${ }^{13}$.

Отказ от своей божественности, поставивший героиню на грань гибели, впоследствии помогает ей пройти все испытания и остаться человеком. В финале романа Ника забирает всех выживших землян на другую планету - Землю-2.

Роман Т. Устименко интересен тем, что героиня, ставшая в конце концов спасителем человечества, сама отказывается от своего божественного статуса. Можно говорить о том, что автор достаточно радикально решает вопрос о богочеловеческой природе Спасителя.

Роман «Богами не рождаются» показывает, что мотив Второго пришествия усвоен и трансформирован фантастикой. Как справедливо отмечает Я. Кротов, образ Христа удобен для авторов: «Обращение к образу Христа задает сразу множество параметров, хорошо знакомых даже религиозно невежественному человеку. На фоне этих параметров легче сказать что-то свое, потому что стандарт очевиден» $[5,245]$. В то же время нельзя не отметить и попыток преодоления заданного стандарта.

Возможность амбивалентной трактовки Спасителя - свидетельство десакрализации образа. Как отмечает М. 3. Мусин, этот процесс «расколдовывания» сакрального элемента ведет к тому, что «происходит ценностно-смысловая девальвация объекта, его возвращение в сферу обыденного» $[9,122]$. Он подчеркивает, что «потеряв статус сакральных, обладающих 
высшим авторитетом и безусловным значением нормы, ценности, идеалы и стереотипы существования в мире перестают быть обязательными к исполнению и преодолеваются» $[9,122]$. На наш взгляд, именно преодоление образа Спасителя и представлено в романах Н. Перумова, Т. Устименко и С. Лукьяненко.

Можно говорить о том, что в современной фэнтези появилась тенденция профанировать сакральные образы, мотивы и сюжеты, что, безусловно, показывает актуальность евангельских сюжетов для массового сознания. Данная проблема, на наш взгляд, заслуживает пристального внимания исследователей.

\section{Примечания}

1 Хлумов В. Старая дева Мария [Электронный ресурc]. URL: http://www.ereading.club/bookreader.php/62106/Hlumov_-_Staraya_deva_Mariya. $\mathrm{html}(17.05 .17)$. Далее цитаты из этого произведения приводятся по данному изданию.

2 Вознесенская Ю. Паломничество Ланселота. М.: Лепта Книга, Вече, Грифъ, 2012. С. 635.

3 Там же. С. 623.

4 Лукьяненко С. Холодные берега. М.: АСТ, 1998. С. 447.

5 Там же. С. 482.

6 Лукьяненко С. Близится утро. М.: АСТ, 2000. С. 27.

7 Там же. С. 379.

8 Там же. С. 380.

9 Там же. С. 374.

10 Перумов Н. Война Мага: Эндшпиль; Конец игры. М.: Издательство «Э», 2017. С. $814,820$.

11 Там же. С. 686.

12 Там же. С. 834.

13 Устименко Т. Богами не рождаются. М.: «Издательство АЛЬФАКНИГА», 2010. С. 340.

\section{Список литературы}

1. Бирюзова Н. А. Мотив Второго Пришествия Христа в русской литературе XIX-XX вв.: на материале произведений Ф. М. Достоевского, М. А. Булгакова, А. и Б. Стругацких, Б. Акунина: автореф. дис. ... канд. филол. наук. - М., 2010. - 18 с.

2. Бойко С. Для бессмертных: инструкции. Православная книга сегодня // Вопросы литературы. — 2014. - №. 5. - С. 61-88. 
3. Есаулов И. А. Русская классика: новое понимание. - СПб.: Алетейя, 2012. - 448 c.

4. Ковтун Е. Н. Художественный вымысел в литературе ХХ века. - М.: Высшая школа, 2008. - 484 с.

5. Кротов Я. Христос под пером // Иностранная литература. - 1998. № 5. - С. 242-253 [Электронный ресурс]. - URL: http://magazines.russ. ru/inostran/1998/5/krotov-pr.html (17.05.17).

6. Крылова М. Жанр христианского постапокалипсиса. «Путь Кассандры, или Приключения с макаронами» Юлии Вознесенской // Вопросы литературы. - 2016. - № 5. - С. 102-113.

7. Кукулин И. Инвентаризация апокрифов // НЛО. - 2006. - № 78. С. 401-408 (Рец. на кн.: Татаринов А. В. Жанровая природа и нравственная философия художественных текстов о евангельских событиях. Краснодар, 2005) [Электронный ресурс]. — URL: http://magazines.russ. $\mathrm{ru} / \mathrm{nlo} / 2006 / 78 / \mathrm{kuku31.html} \mathrm{(17.05.17).}$

8. Кургузова Н. В. Реконструкция мифа в дилогии С. Лукьяненко «Искатели неба» // Миф, фольклор, литература: эстетическая проекция мира. - Вроцлав: Русско-польский институт, 2015. - С. 230-241.

9. Мусин М. 3. Сакрализация и профанизация в развитии культуры // Вестник социально-политических наук. - 2015. - № 14. - С. 122-127.

10. Неёлов Е. М. Христианская традиция в русской фантастической литературе XX - начала XXI века // Проблемы исторической поэтики. Петрозаводск; СПб.: Алетейя, 2011. - Вып. 9: Евангельский текст в русской литературе XVIII-XX веков: цитата, реминисценция, мотив, сюжет, жанр. Вып. 6. - С. 379-388 [Электронный ресурс]. — URL: http:// poetica.pro/files/redaktor_pdf/1455536732.pdf (17.05.17).

11. Павликова Е. А. Жажда истины и отваги: Послесловие // Вознесенская Ю. Путь Кассандры, или Приключения с макаронами. - М., 2004. - С. 689-701.

12. Петухова Е., Чёрный И. Современный русский историко-фантастический роман [Электронный ресурс]. - URL: http://www.fandom.ru/ about_fan/cherny_17_3.htm (17.05.17).

13. Словарь-указатель сюжетов и мотивов русской литературы. Экспериментальное издание / отв. ред. Е. К. Ромодановская. - Новосибирск: Изд-во СО РАН, 2003. - 243 с.

14. Татаринов А. В. Власть апокрифа: библейский сюжет и кризисное богословие художественного текста. - Краснодар: Мир Кубани. 2008. - 712 с. [Электронный ресурс]. - URL: zar-literature.ucoz.ru/ texts/tarinov_a.v-vlast_apokrifa.doc (17.05.17).

15. Чепур Е. А. Герой русской фэнтези 1990-х гг.: модусы художественной реализации: автореф. дис. ... канд. филол. наук. - Магнитогорск, 2010. - 23 c. 
16. Чепур Е. А. Типы характеров русской фэнтези 1990-х гг. как воплощение доминирующих направлений духовного поиска // Проблемы истории, филологии, культуры. - М.; Магнитогорск; Новосибирск, 2010. - Вып. 3 (29). - С. 187-194 [Электронный ресурс]. - URL: http:// pifk.magtu.ru/doc/pifk-03-2010.pdf (17.05.17).

Tatyana I. Khoruzhenko

Ural Federal University named after the First President of Russia B. N. Yeltsin (Yekaterinburg, Russian Federation)

tkhoruzhenko@mail.ru

\title{
THE MOTIF OF THE SECOND COMING IN RUSSIAN FANTASTIC FICTION
}

\begin{abstract}
The motif of the Second Coming of Christ takes a special place in Russian fantastic fiction at the turn of the millennium. In the recent decades allusions to the Gospel topic appears in increasing frequency in the genre of fantasy. The aim of the given article was to analyze the peculiarities of the depiction of the subject of Advent in Russian fantastic fiction. As the basis for the research the novels of Y. Voznesenskaya, N. Perumov, V. Khlumov, S. Lukyanenko and T. Ustimenko are of particular interest. The Advent motif appears in the story line of each of the novels in question. Though, the attitude of the authors to the image of the Savior and his second coming to the world fluctuates: from a respectful expectation (Y. Voznesenskaya, T. Ustimenko, S. Lukyanenko) to the depiction of the Savior as a monster (N. Perumov). The possibility of an ambivalent interpretation of the Savior is the eloquent evidence of desacralization of this image. The profaning of the sacred is one of the tendencies of the modern popular culture. The genre of fantastic fiction, as a product of mass culture, has caught this trend quite precisely.
\end{abstract}

Keywords: Second Coming of Christ (Advent motif), russian fantastic fiction, fantastika, mass literature, Gospel, biblical allusions

\section{References}

1. Biryuzova N. A. Motiv Vtorogo Prishestviya Khrista v russkoy literature XIX-XX vekov: na materiale proizvedeniy F. M. Dostoevskogo, M. A. Bulgakova, A. i B. Strugatskikh, B. Akunina. Avtoref. dis.... kand. filol. nauk [The Motif of the Second Coming of Christ in Russian Literature of the 19th and 20th Centuries: Based on the Literary Works of F. M. Dostoevsky, M. A. Bulgakov, A. and B. Strugatsky, B. Akunin. PhD. philol. sci. diss. abstract]. Moscow, 2010. 18 p. (In Russ.) 
2. Boyko S. For the Immortals: Instructions. An Orthodox Book Today. In: Voprosy literatury, 2014, no. 5, pp. 61-88. (In Russ.)

3. Esaulov I. A. Russkaya klassika: novoe ponimanie [Russian Classics: A New Understanding]. St. Petersburg, Aleteyya Publ., 2012. 448 p. (In Russ.)

4. Kovtun E. N. Khudozhestvennyy vymysel v literature XX veka [Artistic Fiction in the Literature of the 20th Century]. Moscow, Vysshaya shkola Publ., 2008. 484 p. (In Russ.)

5. Krotov Ya. Christ Under the Pen. In: Inostrannaya literatura [Foreign Literature], 1998, no. 5, pp. 242-253. Available at: http://magazines.russ.ru/ inostran/1998/5/krotov-pr.html (accessed 17 May 2017). (In Russ.)

6. Krylova M. The Genre of the Christian Post-Apocalypse. "The Path of Cassandra, or the Macaroni Adventures" by Julia Voznesenskaya. In: Voprosy literatury, 2016, no. 5, pp. 102-113. (In Russ.)

7. Kukulin I. The Inventory of the Apocrypha. In: NLO [New Literary Review], 2006, no. 78, pp. 401-408. (Book Review: Tatarinov A. V. The Genre Nature and Moral Philosophy of the Artistic Texts about Evangelical Events. Krasnodar, 2005). Available at: http://magazines.russ.ru/nlo/2006/78/kuku31. html (accessed 17 May 2017). (In Russ.)

8. Kurguzova N. V. Reconstruction of the Myth in the Dilogy of S. Lukyanenko "Sky Seekers". In: Mif, fol'klor, literatura: esteticheskaya proektsiya mira [Myth, Folklore, Literature: Aesthetic Projection of the World]. Wrocław, The Russian-Polish Institute Publ., 2015, pp. 230-241. (In Russ.)

9. Musin M. Z. Sacralization and Profanation in the Development of Culture. In: Vestnik sotsial'no-politicheskikh nauk [Bulletin of Social and Political Sciences], 2015, no. 14, pp. 122-127. (In Russ.)

10. Neyolov E. M. The Christian Tradition in Russian Fantastic Fiction of the 20th and Early 21st Centuries. In: Problemy istoricheskoy poetiki [The Problems of Historical Poetics]. St. Petersburg, Aleteyya Publ., 2011. Vol. 9: Evangel'skiy tekst v russkoy literature XVIII-XX vekov [The Gospel Text in Russian Literature of the 18th-20th Centuries: Quotation, Reminiscence, Motif, Plot, Genre]. Issue 6, pp. 379-388. Available at: http://poetica.pro/files/redaktor_ pdf/1455536732.pdf (accessed 17 May 2017). (In Russ.)

11. Pavlikova E. A. The Drive for the Truth and the Courage: Afterword. In: Voznesenskaya Yu. Put' Kassandry, ili Priklyucheniya s makaronami [Voznesenskaya Yu. The Path of Cassandra, or the Macaroni Adventures]. Moscow, 2004, pp. 689-701. (In Russ.)

12. Petukhova E., Chernyy I. Sovremennyy russkiy istoriko-fantasticheskiy roman [A Contemporary Russian Historical and Fiction Novel]. Available at: http:// www.fandom.ru/about_fan/cherny_17_3.htm (accessed 17 May 2017). (In Russ.)

13. Slovar'-ukazatel' syuzhetov i motivov russkoy literatury. Eksperimental'noe izdanie [Dictionary Guide of Plots and Motives of Russian Literature. Experimental Edition]. Novosibirsk, Siberian Branch of the Russian Academy of Sciences Publ., 2003. 243 p. (In Russ.) 
14. Tatarinov A. V. Vlast' apokrifa: bibleyskiy syuzhet i krizisnoe bogoslovie khudozhestvennogo teksta [The Power of an Apocryphal Work: A Biblical Plot and Crisis Theology of the Artistic Text]. Krasnodar, Mir Kubani Publ., 2009. 712 p. Available at: zar-literature.ucoz.ru/texts/tarinov_a.v-vlast_apokrifa. doc (accessed 17 May 2017). (In Russ.)

15. Chepur E. A. Geroy russkoy fentezi 1990-kh godov: modusy khudozhestvennoy realizatsii. Avtoref. dis. ... kand. filol. nauk [The Hero of Russian Fantastic Fiction of the 1990s: The Modes of Artistic Implementation. PhD. philol. sci . diss. abstract]. Magnitogorsk, 2010. 23 p. (In Russ.)

16. Chepur E. A. The Types of Characters of Russian Fantastic Fiction of the 1990s as the Embodiment of the Predominant Directions of Spiritual Search]. In: Problemy istorii, filologii, kul'tury [The Problems of History, Philology, Culture]. Moscow, Magnitogorsk, Novosibirsk, 2010, vol. 3 (29), pp. 187-194. Available at: http://pifk.magtu.ru/doc/pifk-03-2010.pdf (accessed 17 May 2017). (In Russ.) 